\title{
1936. La pluma y la espada. Marinetti, Puccini y Ungaretti en el PEN Club argentino*
}

\author{
1936. The Pen and the Sword. Marinetti, Puccini \\ y Ungaretti at the Argentinian PEN Club
}

Celia de Aldama Ordóñez.

ORCID iD: http://orcid.org/0000-0004-0109-8663

Palacký University (Olomouc)

El artículo propone una lectura en clave política del desembarco en Buenos Aires de tres ilustres escritores —Filippo Tommaso Marinetti, Giuseppe Ungaretti y Mario Puccinicon motivo de la celebración del XIV Congreso Internacional del PEN Club argentino. Con el propósito de discernir si los intelectuales viajan como embajadores de las letras italianas o bien como propagandistas del régimen de Mussolini, se reconstruyen los respectivos calendarios de viaje, se rescatan de las notas de prensa de la época las conferencias dictadas durante las tournées y se recogen las impresiones vertidas sobre el país anfitrión en sus bitácoras de viaje.

Palabras clave: Buenos Aires; PEN Club; Escritores Italianos; Fascismo; Arte y Política.

This article proposes a political reading of the arrival in Buenos Aires of three illustrious writers -Filippo Tommaso Marinetti, Giuseppe Ungaretti and Mario Puccini-on the occasion of the XIV International Congress of the Argentinian PEN Club. In order to discern if the intellectuals are traveling as ambassadors of Italian letters or as propagandists of the Mussolini regime, their respective travel schedules are reconstructed, conferences given during the tournées are rescued from the press' chronicles of the time and their impressions of the host country are collected from their travel blogs.

KeYwords: Buenos Aires; PEN Club; Italian Writers; Fascism; Art and Politics.

Copyright: (C) 2019 CSIC. Este es un artículo de acceso abierto distribuido bajo los términos de la licencia de uso y distribución Creative Commons Reconocimiento 4.0 Internacional (CC BY 4.0).

* El presente artículo se ha realizado gracias al apoyo del Ministerio de Educación, Juventud y Deporte de la República Checa, Proyecto IGA_FF_2018_015 (Literaturas y lenguas románicas: tradiciones, tendencias contemporáneas y nuevas perspectivas). La primera versión de este trabajo forma parte de la tesis doctoral de la autora (De Aldama, 2017, 433-462). 
Per questo ogni guerra è una guerra civile: ogni caduto somiglia a chi resta e gliene chiede ragione.

Cesare Pavese

\section{Semblanzas}

La aventura americana de Filippo Tommaso Marinetti, Mario Puccini y Giuseppe Ungaretti comienza tras su embarco en el transatlántico Asina, que atraca en el puerto de Buenos Aires a finales del mes de agosto de 1936. Los tres escritores italianos conforman la delegación invitada a participar en la reunión internacional de «Poetas, Ensayistas y Novelistas» (PEN) que tendría lugar entre el 5 y el 15 de septiembre de ese año. Mientras el vate futurista es ya una figura familiar en los circuitos intelectuales bonaerenses, en parte por ser esta su segunda visita, sus dos acompañantes precisan de una presentación ante el auditorio porteño a pesar de su prestigio en el contexto literario del que proceden. ${ }^{1}$ Será el mismo Marinetti quien dedique un espacio de su primera conferencia, «Letteratura ed arte della nuova Italia», a elogiar a sus dos acompañantes como destacados renovadores de la lírica y la narrativa italianas. Si por un lado Puccini, consagrado a la novela social, brilla con luz propia por su «personalidad indiscutida», Ungaretti representa «la expresión de la nueva poesía», afirma el tercer viajero ante los espectadores argentinos. ${ }^{2}$

$\mathrm{Al}$ atender a las biografías y al perfil ideológico-literario de los visitantes, saltan a la vista una serie de concomitancias que permiten trazar una línea de parentesco entre ellos. Los tres han participado en los actos de combate de la Gran Guerra, han manifestado su adhesión a la ideología fascista y forman parte de la élite intelectual italiana debido a su notoria trayectoria profesional y destacable obra civil. En relación con la peculiaridad que los define como escritores combatientes, es oportuno aludir al contexto beligerante en que se produce la gestación de su actividad literaria. A partir de la correspondencia que mantienen Mario Puccini y Giuseppe Ungaretti desde sus respectivos frentes bélicos, se conocen los avatares de su enrolamiento como jóvenes soldados durante la Primera

1 Los nombres de Ungaretti y Puccini, aunque conocidos por las élites ilustradas argentinas, no tienen el mismo poder de atracción que sus contemporáneos F. T. Marinetti o Luigi Pirandello. La revista Sur, en la que en 1936 se publica el artículo «Ungaretti» de Ernesto Palacio, tiene un papel decisivo en la introducción de distintos nombres de la literatura italiana en la esfera cultural porteña.

2 «El escritor Felipe Marinetti...», La Prensa, 10 de septiembre de 1936. 
Guerra Mundial, sus desplazamientos junto al ejército y las lecturas que ocupan sus horas muertas en la trinchera; ${ }^{3}$ desde allí, en la hostil meseta del Carso, Ungaretti, además de mantener una nutrida correspondencia con el amigo, compone $\mathrm{Il}$ porto sepolto ${ }^{4}$ su primer poemario y uno de los episodios líricos con mayor resonancia en la historia literaria italiana del siglo XX. En el caso de Marinetti, quizás el escritor cuya figura se ajusta con mayor precisión a la de poeta combatiente, ${ }^{5}$ la publicación de su manifiesto Guerra sola igiene del mondo en 1915 coincide con la ofensiva de Italia contra el Imperio austrohúngaro.

Otro rasgo que acomuna la obra de los tres escritores viajeros tiene que ver con el desarrollo de su producción literaria bajo el mandato de Benito Mussolini. Si bien no atañe a este estudio dirimir el tipo de diálogo que mantienen estos intelectuales con el gobierno del Duce a lo largo de las dos décadas de fascismo, resulta oportuno señalar que, a pesar de los episodios de fricción que van a enturbiar la relación de Ungaretti con los altos cargos de la política institucional hacia finales de la década del treinta, ${ }^{6}$ en el momento de su desembarco en el puerto argentino el comportamiento de la comitiva responde al de fieles propagadores de los triunfos de la Italia fascista.

La travesía transatlántica hace de los tres visitantes parte de la nómina de una joven generación intelectual que goza, por primera vez, de una mayor movilidad internacional y que se beneficia de la experiencia del viaje. ${ }^{7}$

3 Así lo documenta la colección epistolar de reciente publicación Lettere dal fronte a Mario Puccini (2015), donde se recogen las cartas que se intercambian ambos amigos durante su participación militar en la Gran Guerra.

4 Este poemario, publicado en Udine gracias al amigo y también soldado Ettore Serra, confluirá con el siguiente título del poeta, Allegria di naufragi, con el que se abre paso un lenguaje singular en la poesía italiana, un lenguaje de alcance más amplio que todo simbolismo o vanguardismo anterior. Edoardo Sanguineti vislumbra en esa nueva sintaxis lírica «il più radicale esempio di rinnovamento formale sperimentato dalla poesia del nostro secolo» (Guglielmino, 1994, 533).

5 Al margen de sus proclamas belicistas y la concepción de la obra literaria como un campo de batalla, en lo que se refiere a su actividad como soldado, Marinetti participa en la primera fase de la ocupación de Fiume e interviene como teniente en la defensa del Piave. Al ser herido en la ingle, es obligado a retirarse, por lo que recibirá dos medallas de bronce. Años más tarde, rondando los cincuenta, se alista como voluntario de las camisas negras en Etiopía y lucha en contra de las tropas rusas en la expedición de ARMIR en la Segunda Guerra Mundial. Muere al regresar del frente ruso.

6 El distanciamiento de Ungaretti con el régimen se produce en la fase de declive que tiene lugar al final de la década del treinta, en que se asiste al resquebrajamiento del modelo imperial. La aceptación de Ungaretti de la cátedra de Literatura Italiana en la Universidad de São Paulo, que le es ofrecida durante su viaje a la Argentina y que ocupa hasta 1942, refleja una voluntad de alejamiento con respecto al nuevo rumbo tomado por la política italiana en los años anteriores a la guerra.

7 En Trento (2008) se ofrecen distintas perspectivas acerca de la nueva movilidad de los escritores entre finales del XIX y principios del XX. 
Mario Puccini, autor de una ingente producción narrativa, ${ }^{8}$ escribe también varios libros en los que recoge los avatares de sus recorridos por Italia, España y Argentina: entre ellos Milano, cara Milano! (1957), Amore di Spagna. Taccuino di viaggio (1938) y L'Argentina e gli argentini (1939), en el que despliega sus impresiones sobre la pampa, el gaucho y el paisaje urbano de Buenos Aires. Por su parte, también Ungaretti publica varios artículos de viaje reunidos en la colección Il deserto e dopo (1961), pero si su obra ocupa aún hoy en día un lugar privilegiado en el Parnaso literario no es por su literatura de viajes, sino por el viraje que su materia poética imprime en la lírica italiana contemporánea. Ungaretti, tres años antes de su visita a la Argentina, había publicado una de sus obras maestras, Sentimento del Tempo (1933), título que pone en marcha el proceso de monumentalización de su figura como procreadora de la palabra «pura» y de su obra como precursora del hermetismo poético florentino. ${ }^{9}$

\section{Vis a vis}

Con motivo del XIV Congreso Internacional de los PEN Clubs, ${ }^{10}$ sus presidentes, Carlos Ibarguren y Victoria Ocampo, convocan en la capital argentina una multitudinaria reunión de escritores procedentes de Europa, Asia y América. Si bien las normas de la organización, nacida en 1921 como una entidad exclusivamente literaria, insisten en la abstención del juicio político durante las disertaciones oficiales, «algunos congresistas, en concreto aquellos procedentes de una Europa en plena convulsión, participan en las sesiones ordinarias con el ímpetu de quien desciende al campo de batalla». ${ }^{11}$

8 Además de libros de viaje y ensayos literarios, escribió novelas como Viva l'Anarchia (1920), Dov'è il peccato è Dio (1922), La vera colpevole (1926), Il soldato Cola (1927), Ebrei (1931), La prigione (1932) y Ritratto d'adolescente (1936). También es autor de libros de relatos como Essere o non essere (1920) y Racconti cupi (1922), y libros de memorias como Ritratti e interni (1936) y La terra è di tutti (1958). Sus viajes por España, y en concreto su paso por Sevilla, explican su amistad con los intelectuales de la España republicana, sobre cuyas figuras escribirá algunos ensayos literarios como Miguel de Unamuno (1924) o Vincenzo Blasco Ibáñez (1926).

9 No puede pasar por alto, advierte Guglielmino a propósito de Sentimento del tempo, «il grande influsso che esercitò quest'ultima raccolta sugli ermetici propriamente detti, in virtù del più elaborato e prezioso simbolismo, dell' analogismo più criptico e del linguaggio più incline a recuperare le movenze del canto» (Guglielmino, 1994, 535).

10 Se trata de la primera reunión de los PEN Clubs celebrada fuera de Europa y responde a la política cultural de Agustín P. Justo (1932-1938), que se compromete a cubrir los gastos de viaje y el alojamiento de todos los invitados para construir una imagen mejorada de la Argentina. Las actas se publicaron el siguiente año: PEN Club de Buenos Aires, XIV Congreso Internacional de los P.E.N. Clubs, 5-15 septiembre 1936: discursos y debates, Buenos Aires, Gerónimo J. Pesce, 1937.

11 De Aldama, 2018, 74. 
El enfrentamiento entre los representantes de las distintas naciones — «la dramática disensión entre los delegados franceses y los italianos», en palabras de Roberto Giusti- ${ }^{12}$ es sintomático de la irradiación hacia el campo intelectual de las desavenencias ideológicas que fracturan el paisaje político occidental. La batalla de ideas involucra, de manera casi unánime, a las filas literarias, cuyos representantes se ven compelidos a redefinir su rol social, a tomar postura en uno u otro bando. Las sesiones del PEN Club se convierten, entonces, en zonas de combate donde los defensores de los ideales democráticos y los simpatizantes del fascismo, al encontrarse cara a cara, se increpan, se lanzan acusaciones y desatan varios altercados. En la creación de tal ambiente de desorden y excitación no participan únicamente los congresistas, sino también el público porteño en general que, amontonado en las barras, asiste bullicioso y resuelto al discurrir de las batallas verbales. La enorme expectación que suscita entre los ciudadanos la reunión de escritores es prueba, según el parecer de Giusti, de una ciudad «vibrante y receptiva». ${ }^{13}$ Por su parte, el delegado chileno Domingo Melfi, partícipe de los acalorados debates como observador silente, escribe en su cuaderno de notas: «Es difícil que el ambiente pueda sustraerse a la presión trágica de la angustia que padece el mundo partido en dos mitades», cuyo rumor afiebrado «llega hasta el congreso. Fascistas y antifascistas llenaban los asientos». ${ }^{14}$ Las actas del congreso, así como las noticias de los diarios publicados en Buenos Aires, ${ }^{15}$ brindan el material necesario para reconstruir el ambiente de crispación en que se desarrollan las reuniones, cuyos protagonistas, ya sean europeos o argentinos, se encuentran inmersos en un contexto de extrema politización que alcanza, en la segunda mitad de la década, su expresión más feroz. ${ }^{16}$

12 Giusti, 1936, 50.

13 Ibidem, 51. Cabe recordar aquí las observaciones de Paula Bruno (2014) acerca de la vitalidad cultural de la capital argentina en el primer tercio del siglo.

14 Melfi, 1936, 13 y 34.

15 Celina Manzoni recuerda que la celebración del congreso se vive como un verdadero «acontecimiento mediático», seguido de cerca por la prensa, la radio y las revistas (Manzoni, 2005, 3). Son de enorme valor las noticias recogidas de los diarios, pues estos no permanecen ajenos a las dos posturas antagónicas, sino que participan desde sus resortes informativos en los respectivos frentes en disputa. Los retratos que se proponen de los intelectuales fascistas varían de periódico en periódico y dejan entrever posturas inconciliables en las distintas fracciones intelectuales.

16 Entre los detonantes de tal extremismo cabe destacar el estallido de la guerra civil española en julio de ese mismo año, la radicalización de la violencia fascista, el avance de otros regímenes totalitarios en Europa y la promulgación en Italia de las leyes raciales a partir de 1938. También Roberto Giusti, en su balance del congreso, ve en la vehemencia del encuentro el reflejo de «un momento histórico tormentoso» (Giusti, 1936, 61). 
La comisión organizadora del congreso de 1936, compuesta por Antonio Aita, Juan Pablo Echagüe, Arturo Capdevila, Manuel Gálvez, Juan B. Terán, Julio Fingerit, Baldomero Fernández Moreno, Oliverio Girondo, Eduardo Mallea y Gustavo Adolfo Martínez Zuviria —más conocido como Hugo Wast-, se hace cargo de cuarenta y un países y más de cien invitados, entre los que destacan personalidades de elevado prestigio en el mundo internacional de las letras. Algunos de esos nombres son Alfonso Reyes, embajador de México en Buenos Aires; los españoles Enrique Diez Canedo y José Ortega y Gasset; los franceses Jules Romains, George Duhamel y Jacques Maritain; el alemán Emil Ludwig; el belga Henri Michaux; el polaco Jan Parandowski y el austríaco Stefan Zweig. Tras el conciliador discurso de bienvenida, a cargo del Dr. Carlos Ibarguren, y la lectura de los mensajes de saludo enviados por George Wells y André Gide a los congresistas desde el otro lado del Atlántico, las primeras hostilidades toman cuerpo con la réplica de Marinetti a las declaraciones de Victoria Ocampo — «la más rica y bella mujer de Buenos Aires, Ocampo, reina de un salón de bolchevismo esnobista», ${ }^{17}$ tal y como la describirá el futurista en sus memorias- acerca del common reader. El tono de querella que inaugura la primera sesión del congreso va in crescendo y encuentra en el líder futurista, espoleado por sus dos acompañantes, a su principal animador. La mañana siguiente, Ludwig, en su tiempo de exposición y acorde con el tema central, «Función posible del escritor en la sociedad», refiere la crítica situación vivida por los escritores germanos bajo el gobierno del Führer. $\mathrm{Al}$ tomar la palabra en nombre de los alemanes emigrados y exiliados, se levanta de las galerías un estruendo de aplausos que convierten a Ludwig, según el testimonio de Melfi, en «héroe de la jornada». ${ }^{18}$ Su denuncia se propone visibilizar episodios como la quema de libros y la persecución de los intelectuales, así como denigrar la figura del escritor oficial del Tercer Reich, aquel que encuentra su acomodo en el régimen del nazismo bien como burócrata, bien como trovador a sueldo. Sus alusiones, aunque no apuntan directamente a los invitados fascistas, soliviantan a los italianos, que interrumpen al alemán con griteríos y, en el caso de Marinetti, con un discurso en defensa de la libertad de expresión que se vive en la Italia del Duce. A partir de esta segunda intervención del futurista, se sucede entre la delegación francesa, representante del ala democrática, y la italiana, defensora del modelo fascista, una cadena de hostilidades que terminan por

17 Marinetti, 1969, 323.

18 Melfi, 1936, 29. 
fagocitar todos los espacios de discusión literaria. La figura del escritoresteta, amurallado en su torre de marfil y centrado en el objeto estético, no tiene cabida en esta reunión de «educada beligerancia». ${ }^{19}$

La controversia más violenta entre ambas se da en la sesión del día 8 de septiembre, durante la cual Marinetti, encargado de la presidencia de la mesa, es interpelado por Duhamel y Romains con relación a su polémico texto Guerra sola igiene del mondo. Carlos Ibarguren sale en defensa del acusado, que esquiva las alusiones mediante la delación del acoso al que son sometidos los representantes de la Italia fascista por parte de los franceses durante las sesiones. ${ }^{20}$ En las jornadas restantes se aplaca la participación de la comitiva italiana, que en la sesión de clausura, y siempre a través de su portavoz más altivo, propone la ciudad de Roma como sede del próximo congreso del PEN Club. El balance de Melfi al término de los debates es que «Europa dominaba el Congreso», ${ }^{21}$ mientras que los delegados hispanoamericanos asisten con estupefacción al transcurrir violento de las disputas. Stefan Zweig, del que Melfi evoca la afabilidad y la tristeza, toma la palabra únicamente en la sesión de clausura durante la cual rinde homenaje a H. G. Wells, al que presenta ante el auditorio como «gran escritor y combatiente infatigable», para insistir en la «potencia moral» y misión ecuménica del artista y del pensador. ${ }^{22}$

La transmisión del desarrollo del congreso por parte de la prensa argentina denota una clara escisión ideológica de la misma. En un extremo, desde periódicos como Crítica y L'Italia del Popolo se abomina de los representantes italianos a la par que se elogia el discurso de Jules Romains,

19 Manzoni, 2005, 10. Al respecto apunta Niall Binns: «este clima de violencia, esta imposibilidad de alejar la política de los debates intelectuales, tuvo como trasfondo la exaltación ideológica suscitada en esas semanas por la guerra civil española, que había empezado menos de dos meses antes» (Binns, 2012, 37).

20 Transcribimos aquí parte de una de las crónicas que describe el clima de hostilidad que se vive durante la jornada del 8 de septiembre: «Los gritos y ademanes desmedidos no cesaron durante largo rato. Rojo e inmóvil en el sillón, con las venas fuertemente marcadas sobre la frente, Marinetti esperaba. Ungaretti, con el brazo extendido y el cabello revuelto, apostrofaba a Cremieux y a Romains. En inglés, en francés, en alemán, en portugués, en español, en italiano y en lenguas casi incomprensibles saltaban los vocablos. Todos los delegados hablaban a un tiempo» («Las dos tendencias políticas del congreso», La Nación, 9 de septiembre de 1936, 10).

21 Melfi, 1936, 39.

22 Ibidem, 173. Recuerda Melfi las palabras de Zweig en una conversación privada con el escritor: «Media Europa gime bajo cadenas y los escritores tenemos una misión muy difícil, por no decir terriblemente peligrosa. [...] El mundo europeo se ha habituado a una idea desconsoladora y trágica, la de que todo terminará en una hecatombe peor que la de 1914. [...] Toda la literatura está impregnada, inficionada, saturada de angustia, de sobresalto. Escribimos como si estuviéramos en el último día de la paz» (Ibidem, 20). 
miembro de la delegación francesa y principal contrincante de Marinetti. Los postulados bélicos del futurista, leídos en los años veinte en clave metafórica, devienen literales e inadmisibles en 1936; ya no representan el pensamiento iconoclasta frente a doctrinas caducas, sino que evocan el yugo de las democracias europeas y, en concreto, la lucha en las trincheras españolas:

Caro futurista, non ne imbrocchi una! É proprio il caso di dirti: vai a igienizzare le narici con gli olezzanti profumi delle trincee occupate dai ribelli spagnoli! Trincee e cessi sono una sola cosa... Lo strano è che il fautore della sola igiene del mondo ignori che anche una guerra civile e i suoi occhi e le sue narici possono deliziarsi con tutte le porcherie che va predicando in abito la società. Altro che venire a Buenos Aires a schernire la dea sublime degli uomini liberi e puliti!23

En el diario antifascista, el retrato que se ofrece de la actuación de la comitiva italiana es el de un «spettacolo pietoso». Sus miembros, substraídos del aparato legitimador que los ampara dentro del contexto dictatorial, no son capaces de persuadir al auditorio de la ecuanimidad del gobierno del Duce. En la trifulca entre fascistas y antifascistas queda al descubierto el carácter nervioso y violento de los visitantes italianos pues, ante las recriminaciones de sus contendientes, «perdono il controllo di sé stessi, balbettano e si confondono». ${ }^{24}$ La Nuova Patria degli Italiani coincide con el diario anterior a la hora de informar de la bochornosa participación de los intelectuales fascistas en el PEN Club, esta vez mediante una noticia que adopta la forma de un poema paródico en que cada uno de los tres intelectuales realiza una presentación burlesca de sí mismo:

Mari Netti: Io amo la guerra/ ma, se più vi piace,/ invoco la pace/ per gli altri e per me. Unga Retti: Io sono poeta/ ma, sopra ogni cosa/ mi piace la prosa/ dell'urlo volgar.

P. Uccini: Io sono scrittore/ di quelli... puccini,/ ma so a Mussolini/ le scarpe lustrar.

I tre: Quiaggiú siam venuti/ soltanto per spasso/ per far del fracasso/ e farci... fischiar. ${ }^{25}$

Crítica, que sigue día a día las sesiones del PEN Club, cuenta entre sus periodistas con el exiliado antifascista Mario Mariani que, a medida que avanza el congreso, se levanta en oposición frontal ante sus compatriotas. En un primer artículo, que coincide con la jornada de inauguración, Mariani denuncia la obra de propaganda perpetrada por los viajeros y, frente al trío

23 «La libertà italiana dell'igienista Marinetti», L'Italia del Popolo, 11 de septiembre de 1936.

24 «Uno spettacolo pietoso», L'Italia del Popolo, 9 de septiembre de 1936.

25 «Pen Club», La Nuova Patria degli Italiani, 13 de septiembre de 1936. 
fascista, propone a Giovanni Papini, Luigi Pirandello y Benedetto Croce como los tres únicos nombres de las letras italianas contemporáneas que merecen el prestigio internacional. La delegación italiana es boicoteada por los interlocutores del PEN Club pero también por algunos medios informativos, que lisonjean a los delegados franceses como vencedores del debate en contraste con los tres «fantoches» italianos. ${ }^{26}$ Uno de tantos ejemplos aparece en una noticia de Crítica el 9 de septiembre, en la que Marinetti es caricaturizado en actitud descompuesta frente a un imperturbable y sereno Jules Romains: ${ }^{27}$

Mientras Romains leía fríamente, imperturbable, la enérgica declaración de la delegación francesa, Marinetti, rojo hasta el extremo, enjuagaba la transpiración que corría por la cara. El delegado fascista no estaba pasando evidentemente un buen momento. Pero apenas dio fin a su exposición el delegado francés, Marinetti se puso en pie violentamente. No atinó a pensar en la necesidad de conservar cierta corrección. Se bebió toda el agua que tenía en su vaso y dio comienzo, desordenadamente, a una exposición violenta que culminó en un ataque directo a la delegación francesa. ${ }^{28}$

En este mismo diario, los alborotos desatados por el encontronazo entre intelectuales italianos y franceses se toman como pretexto para denunciar la censura intelectual que se vive en el país sudamericano y señalar la connivencia de las élites culturales argentinas con el fascismo, tal y como prueba la simpatía que sienten por los invitados italianos «los directores del PEN Club, los Gálvez, los Ibarguren, los Martínez Zuviría»:29

La Argentina no es en la actualidad un país en el que impere el régimen de las libertades democráticas. En la Argentina se procesa a los poetas y los escritores por el delito de expresar literariamente su repulsa a la injusticia social imperante y su esperanza de un mundo más equitativo. Hay en las cárceles estudiantes que purgan el atentado de lesa patria de haber adherido a la causa de nuestros trabajadores. [...] En la Argentina todas las instituciones oficiales vinculadas con el problema de la cultura están, prácticamente, en manos del fascismo. ${ }^{30}$

26 Manzoni recuerda la mirada escéptica de Zamora en Claridad ante un congreso caracterizado por la falta de representatividad de la izquierda argentina. Zamora retrata a los delegados italianos como «bufos destinados a representar un grotesco papel» en la medida que, bajo la «tiranía fascista», los escritores sólo «desempeña[n] una función puramente mecánica» (Manzoni, 2005, 16).

27 También Melfi $(1936,12)$ destaca la «serenidad perfecta» de Jules Romains, «el hombre más aplaudido del congreso».

28 «Se avergonzó de su discurso el fascista Marinetti», Crítica, 9 de septiembre de 1936, 1.

29 «El congreso resultó antifascista y antiguerrero», Crítica, 8 de septiembre de 1936, 1.

30 «El PEN Club de Buenos Aires vive ajeno a la realidad del mundo», Crítica, 8 de septiembre de 1936. 
Las notas amables que La Nación publica sobre las virtudes declamadoras del futurista, que «habló en italiano, impetuosamente, espléndidamente, con un vigor que nacía de la seguridad exacta de sus principios y con una fluidez que era fruto de una larga experiencia», ${ }^{31}$ pueden leerse como un testimonio de la devoción que los sectores conservadores rinden a la figura marinettiana. Por lo que respecta a periódicos filofascistas como Crisol, Il Giornale d'Italia o Il Mattino d'Italia, estos prefieren desentenderse de las reuniones y debates que tienen lugar en el marco del PEN Club, cuyas sesiones anuncian con parquedad. Il Giornale d'Italia publica un solo artículo al respecto, firmado por Folco Testena y titulado «Il libro e la madia», en el que resume la celebración del congreso como un fracaso. Por su parte, Il Mattino d'Italia dedica solamente dos columnas al comentado evento; en la primera, «Il rito della sputacchiera al PEN Club», el encuentro intelectual es presentado como una reunión entre escritores anarquistas, bolcheviques e incendiarios, y se ironiza sobre la inconstancia de las opiniones políticas de Ocampo, que dos años antes había visitado al Duce en Italia. Asimismo, se recuerda la misión civil del poeta en el régimen fascista y se ensalza a Marinetti como «el primo poeta moderno che abbia spinto l'uomo verso le nuove sofferenze perchè fosse in grado di creare la nuova potenza. Marinetti ha liberato il popolo italiano dalla paura della sofferenza dandogli in dono la gioia della conquista». ${ }^{32}$ En el segundo artículo, firmado por Mario Intaglietta, la fracasada «emboscada» que Romains y Cremieux preparan contra Marinetti sirve para recrear la imagen del futurista como un poeta soldado imbatible y comprometido con la raza y el destino de su nación:

Romains e Cremieux hanno il bel compito di eliminare Marinetti dal Club. Hanno assunto un atteggiamento politico per colpire il poeta che fa della politica. Già durante l'impresa italiana in Africa il PEN Club aveva tentato radiare Marinetti perché combattente e soldato. Ma il colpo non era riuscito [...] I clercs mancati vogliono sconfessare un poeta soldato, dimenticando che ad altro poeta soldato la civiltà europea deve se la forza e la violenza non hanno prevalso sul diritto e sulla giustizia. Dimenticando che se Roma civilizzatrice non ha piegato sotto la barbarie etiopica si deve al coraggio civile e militare di un popolo di poeti e di soldati [...] Si voleva offrire alla democrazia la testa di Marinetti. Il colpo non è riuscito perché Marinetti sa difendere la sua testa e più ancora le sue idee. Il Fascismo affronta tutte le battaglie. Marinetti è venuto a Buenos Aires non per difendersi da un' accusa miserabile ma per chiarire a missione del poeta in regime fascista. Missione che è altamente civile come al tempo della Grecia. Il poeta fascista opera in mezzo al popolo. Ne vive le passioni,

31 «En ambiente a ratos muy caldeado», La Nación, 9 de septiembre de 1936, 4.

32 «ll rito della sputacchiera al PEN Club», Il Mattino d'Italia, 10 de septiembre de 1936, 4. 
ne stimola le forze, ne giustifica le speranze. Il poeta fascista è quello che ubbidisce alla legge della propria razza e sa affermare la poscia sul campo di battaglia. ${ }^{33}$

La desproporción entre las noticias sobre el PEN Club y aquellas dedicadas a reproducir las conferencias y entrevistas de los tres viajeros constituye, sin lugar a dudas, una manera de atenuar las resonancias del bochorno italiano en la reunión de los escritores. El silencio de algunos medios como estrategia periodística se alterna con el insulto en diarios filo-fascistas argentinos como Crisol, donde se refiere con desprecio al carácter masónico y judaico de los congresistas:

Vamos a referirnos ahora un poco a lo ridículo e histriónico de las bizantinas discusiones que constituyen el Congreso del PEN Club. Este Congreso del PEN Club es una ridícula behetría, un ir y venir de palabras en cincuenta idiomas, en fin una sesión a cargo de forasteros más o menos intrusos, más o menos vacuos, más o menos cándidos. La pobreza intelectual de este Congreso es algo que ya preveíamos, pese a los Marinetti y los Ungaretti y algún otro, que se prestan a la farsa. El literato es el ser díscolo, vacuo y estéril, por excelencia, una vez sustraído a su oficio propio. El literato debe relegarse a su literatura y no salir de ella. ${ }^{34}$

En las crónicas publicadas por los diarios argentinos de izquierda como Crítica, mientras Marinetti ocupa la centralidad de las reyertas y es identificado como el promotor de las batallas verbales, las voces de Giuseppe Ungaretti y Mario Puccini apoyan al futurista desde una retaguardia bulliciosa que alborota las sesiones con sus aspavientos e increpa a los contrincantes franceses. Si las actas del congreso evidencian cómo ninguno de los tres respeta los turnos de palabra, las crónicas de la prensa describen su participación como un acopio de gritos, muecas y ademanes. Las noticias parecen retrasmitir un combate entre púgiles donde la templanza de los invitados alemanes entra en colisión con la irascibilidad de los italianos. ${ }^{35}$ Los atributos físicos de la delegación fascista, la mandíbula altiva de Marinetti, los ojos terribles de Ungaretti, corresponden con la actuación extemporánea mantenida durante los debates, que termina por frustrar cualquier amago de diálogo literario; mientras sus exclamaciones iracundas aumentan los

33 «Il colpo fallito», Il Mattino d'Italia, 10 de septiembre de 1936.

34 «La frívola inanidad del sospechoso PEN Club», Crisol, 9 de septiembre de 1936, 1.

35 «Stephan Zweig, de rostro simpático y expresión serena, estaba sentado al lado de Emil Ludwig, en la primera fila. Más allá, Marinetti, con su altiva mandíbula; Ungaretti, ojos terribles y espaciada frente, y Puccini, ágil, movedizo, vibrante». «El Congreso del P.E.N. Club. Oratoria, túnicas y champagne», La Fronda, 6 de septiembre de 1936. 
decibelios de la sala, las silbas y réplicas que les devuelven desde las tribunas del público envuelven las sesiones en una atmósfera de incomunicación:

Comienza Marinetti a explicar su situación. Habla primero en francés y va subiendo de tono. Dice las palabras finales con alaridos, las afirma con golpes de puño y en esos momentos Ungaretti y Puccini, que han estado tascando el freno, estallan: ¡Canaggia! ¡Canaggia! - vocifera Ungaretti. Puccini grita como un loco «iDesgraciatto!» Ungaretti sigue gritando en varios idiomas «Canaggia, Trompeur». El momento es terrible. Como los gritos han estallado mientras Marinetti hablaba, este grita a su vez y da unos puñetazos capaces de romper el cráneo a un guerrero abisinio. ${ }^{36}$

Entre los cuadros memorables de la delegación italiana, merece destacarse aquel en que Crítica retrata al poeta italiano Giuseppe Ungaretti en su pose más disgustada, refiriendo la exasperación alcanzada durante los debates. Esta escena evoca otro combate ocurrido años atrás en la villa romana de Luigi Pirandello, el duelo con espadas en el que se baten Ungaretti y Bontempelli por maledicencias literarias:

En el mismo momento en que Marinetti se puso en pie entre los siseos del público, sus compañeros de delegación, Ungaretti y Puccini, exhibían al público un espectáculo completo del estado de furia más inobjetable. Algunos médicos que se hallaban en el auditorio convinieron en que el triple caso de la delegación italiana tenía interés clínico, varios dibujantes ávidos de documentos humanos sacaron apuntes y algunos novelistas tomaron apresuradas notas. Desmelenado, gesticulando desesperadamente, arrojando desde sus bancas violentos directos con ambas manos en dirección de las bancas de la delegación francesa, Ungaretti gritaba estentóreamente: «iCanallas! ¡Provocadores de guerras! ¡Canallas!». ${ }^{37}$

En su balance del congreso, Susana Shirkin describe las sesiones como el espacio en que se reproducen en miniatura los enfrentamientos vivos en el Viejo Continente..$^{38}$ En el XIV Congreso Internacional de los PEN Clubs se libra también una batalla de la que nadie parece salir vencedor o quedar satisfecho: por un lado, los diarios filofascistas apuntan a la inutilidad del encuentro y sentencian que se ha tratado de una emboscada preparada para los invitados italianos; por otro, los diarios de la izquierda argentina

36 «Un escándalo en el PEN Club. El match entre las delegaciones francesas e italianas», La Fronda, 9 de septiembre de 1936.

37 «El disgusto de Ungaretti», Crítica, 9 de septiembre de 1936, 4.

38 «La expectativa potenciada por la prensa local e internacional, los decibeles en ascenso del clima político europeo y vernáculo y las disímiles ideologías y personalidades de los delegados, convertían las sesiones del Congreso en un simbólico campo de batalla paralelo del que se gestaba en el Viejo Mundo. Para todos los miembros asistentes resultaba claro que era casi imposible sustraer las referencias políticas de los discursos», Shirkin, 2007, 4. 
comparten la sensación de fracaso debido a una nómina incompleta de invitados, que no incluye a representantes legítimos del pensamiento moderno como Valéry, Unamuno, Papini o Pirandello. A partir de estas ausencias, Mario Marini cuestiona desde las páginas de Crítica el valor intelectual de las deliberaciones allí concluidas, «tomadas en nombre de la intelectualidad internacional por hombres dotados de la autoridad espiritual de Fidelina de Figueredo, Vermeylea, Pièrard y los demás Ungaretti». ${ }^{39}$

\section{Los congresistas fuera del congreso}

Il Mattino d'Italia anuncia el 29 de agosto de 1936 la llegada de los tres eminentes escritores italianos, cuya travesía ${ }^{40}$ — que se prolongará hasta mediados de octubre - incluye, además de una tournée de conferencias en Buenos Aires y otras ciudades del interior (Rosario, Córdoba, Bahía Blanca y Santiago del Estero), varias visitas oficiales, entrevistas en los principales diarios nacionales y la mencionada participación en las sesiones del PEN Club. Las distintas actividades abarrotan durante varios días los circuitos culturales bonaerenses, cuyos intelectuales siguen con avidez los pasos de los italianos por la capital. La llegada de los ilustres escritores coincide con un turbulento paisaje político, controlado desde comienzos de la década por gobiernos fraudulentos de ideología conservadora y por la marcada politización de sus intelectuales. Frente a la propagación de las noticias acerca de ascenso de los totalitarismos europeos, la comunidad letrada argentina — sostiene Niall Binns - experimenta un cisma irreversible entre simpatizantes y detractores del fascismo, acentuado por el reciente estallido de la guerra civil española. ${ }^{41}$ Los episodios locales y la empatía hacia los acontecimientos internacionales explican la primacía de la discusión política sobre la disquisición estética, que es relegada a un segundo plano arrastrando consigo las aventuras vanguardistas de la década anterior. Marinetti, al atracar por segunda vez en la ciudad que diez años atrás lo había acogido como célebre embajador de la «nueva sensibilidad» europea, encuentra ahora un panorama intelectual mayoritariamente hostil en el que

39 «Balance de un fracaso. El congreso de los bizantinismos estériles», Crítica, 14 de septiembre de 1936.

40 Se reconstruyen aquí los calendarios de la comitiva de 1936, a excepción del correspondiente a la gira de Marinetti, a la que he dedicado un estudio exclusivo en el artículo «Un futurista en apuros: los viajes trasatlánticos de Marinetti», Letterature d'America, XXXIV, 151-152, Roma, 2014, 69-83.

41 Binns, 2012. 
el futurismo, estigmatizado como instrumento del ideario mussoliniano, ocupa un lugar de desprestigio en la República Argentina. Pese a tal desinterés por su credo estético, el segundo desembarco provoca un impacto relevante en el país sudamericano, pues es aprovechado por el fascismo de ultramar como ocasión para celebrar los triunfos de Mussolini, que a mediados de los años treinta reúne en torno a sí un especial consenso debido a las victorias en África y la proclamación del Imperio.

La primera noticia que anuncia la llegada del ilustre huésped Marinetti es la que se publica el 25 de agosto de 1936 en el diario fascista Il Mattino d'Italia con el titular: «Il Seniore futurista torna dall'Africa e viene a Buenos Aires». Neptunia es el nombre del transatlántico que, procedente de Trieste, atraca en la capital argentina, donde, el mismo día del desembarco, el viajero pronuncia su conferencia «Testimonianza di un poeta soldato in Africa Orientale» y trasmite un mensaje personal del Duce a los italianos de Argentina. Con talante abiertamente político, inicia así su segunda gira americana que, si bien incluye en el viaje de retorno una breve escala en Uruguay y otra en Brasil, limita la mayor parte de sus actividades a la ciudad de Buenos Aires, donde permanece hasta la fecha de regreso el 20 de septiembre. Tal y como se ha podido comprobar en las notas de prensa de los diarios consultados, el calendario de visitas, al margen de su participación en las reuniones del PEN Club, incluye pocas actividades de índole literaria y numerosas diligencias de representación oficial. Esta vez Marinetti dicta solamente dos conferencias en Buenos Aires, una en italiano y otra en francés, que repetirá en dos ocasiones (el 29 de agosto y el 9 de septiembre) en el Teatro Politeama: «Letteratura ed arte della nuova Italia» $\mathrm{y}$ «Politique et poesie futuriste. 1936». Los contenidos de ambas disertaciones versan, de manera general, sobre los hallazgos alcanzados bajo el régimen fascista por la arquitectura, la música, la literatura y las artes plásticas. Para sustentar esta tesis, el orador recurre al panegírico de figuras coetáneas como la de Mario Puccini, ensalzado por su «personalità libera dalle influenze dannunziane», la de Massimo Bontempelli, «novelliere elegante, snello, elettrico», la del arquitecto Sant 'Elia, caído en el frente de batalla, la de Aldo Giuntini, «creatore delle sintesi musicali» o la de Luigi Pirandello, apodado el «Sardou centuplicato». ${ }^{42} \mathrm{La}$ tercera y última perorata que dirige a los argentinos, esta vez en Mendoza el 18 de septiembre, se desliga de asuntos artísticos, limitándose a referir las victorias de Mussolini en África

42 «Marinetti riafferma», Il Mattino d'Italia, 11 de septiembre de 1936, 5. 
Oriental; con ella engrosa, una vez más, el discurso patriótico que propaga en los confines bonaerenses.

El resto de sus apariciones públicas podrían dividirse en dos tipologías: por un lado, las visitas propagandísticas de carácter político-oficial y, por otro, los homenajes y encuentros ociosos con algunos representantes de la cultura argentina. Entre las visitas, las más relevantes son al Fascio femenino el día 5 de septiembre, a los «Dopolavoristi della Marconi» y a la Asociación Patriótica Italiana el 6, a la Dante Alighieri y al Club Italiano de la calle Rivadavia el 12, a la «Scuola Elementare Italiana» el 17 y, por último, a la sede del Fascio el 19, donde refiere las acciones renovadoras de la juventud italiana bajo la guía del Duce desde su etapa como periodista hasta la proclamación del Imperio. El poeta soldado, recibido con júbilo en las sedes institucionales, complace a su auditorio con arengas inflamadas de patriotismo en las que relata las corajudas acciones de las camisas negras en las tierras abisinias. Marinetti, investido por Mussolini como Accademico d'Italia, cumple así con el itinerario propio de un emisario del régimen. ${ }^{43}$

En lo que se refiere al calendario previsto para Mario Puccini, este obsequia al público argentino con varias disertaciones que se inauguran con la conferencia «Le bellezze nascoste della vecchia Roma», presentada por Manuel Gálvez y pronunciada el día 2 de septiembre en la Facultad de Filosofía y Letras de la Universidad de Buenos Aires. ${ }^{44}$ El 7 de septiembre tiene lugar su segunda conferencia, «Epopea italiana dal maggio 1915 al maggio 1936», en el Circolo Italiano, donde se reúnen autoridades diplomáticas y consulares, eminentes exponentes de la colectividad italiana e ilustres exponentes de la intelectualidad argentina. También en esta ocasión recibe una presentación encomiosa, esta vez por parte del presidente de la Asociación Dante Alighieri:

Vedremo ancora questa sera come l'anima dello scrittore e dell'artista si fonda con l'anima del patriota. E la patria, la nostra patria rivivrà dinanzi a noi nelle vicende tristi e liete di questi ultimi venti anni, così densi di storia e di gloria, rievocati dall'affascinante parola di Puccini. ${ }^{45}$

43 Una rutina similar tiene lugar en su única jornada de paso por Montevideo, durante la cual visita el Hospital Italiano, la Escuela Italiana, se reúne con el presidente Terra y almuerza en el Circolo Italiano. Por la tarde, da una conferencia en el Teatro Sodre y parte hacia Brasil, última escala antes de emprender el regreso a Italia.

44 «Mario Puccini disertó sobre las bellezas de Italia», La Nación, 3 de septiembre de 1936. 1936.

45 «Mario Puccini per la Dante al Circolo Italiano», Il Giornale d'Italia, 8 de septiembre de 
Puccini principia su discurso con referencias a la Gran Guerra, en concreto a la victoria de Vittorio Veneto y del Carso para, a continuación, enumerar las glorias de Mussolini como soldado y adalid del pueblo italiano y completar su arenga patriótica con la exaltación de la joven Italia fascista. Il Mattino d'Italia transcribe extensos fragmentos de la intervención, en la que el drama de la guerra sirve de preámbulo para dar paso a la loa de «le virtù creative e costruttive della nostra razza che ha trasformato terre infette e desolate in ridenti giardini e città moderne, operose e piene di vita». El visitante concluye con un mensaje de optimismo que anuncia un «avvenire solare» para una nación que ha dado tantas muestras de «vitalità e di perenne giovinezza» ${ }^{46}$ Puccini prosigue su periplo en la ciudad de Rosario, donde pronuncia el panegírico «Mussolini e la sua vittoria sul tempo e sugli uomini», un discurso que retoma en Bahía Blanca el 1 de octubre y que funciona como soporte para un torrente de imágenes que buscan reproducir en ultramar el imaginario triunfal edificado por la cúpula fascista. En ambas ciudades, el escritor delinea el paso de «la mediocre società dell' antiguerra in continua decadenza» hacia «un nuovo orizzonte aperto dalla la voce ruda e nuova di Mussolini». La obra del Duce, «condottiero deciso e sicuro», es interpretada como la culminación de la obra del Risorgimento iniciada por Giuseppe Garibaldi y Giuseppe Mazzini. ${ }^{47}$ El retrato que ofrece del jefe de Estado a la colectividad italiana afincada en las orillas rioplatenses corresponde al de una personalidad excepcional que ha logrado desadormecer a una civilización en decadencia:

Ecco il Duce, l'uomo dal coraggio nuovo spingere il popolo al lavoro della guerra; eccolo nell'azione del dopoguerra essere lo spirito vigile e vivo dell'Italia sanguinata e mutilata. Intorno a lui si raccoglie la vitalità della razza che sente che la guerra non è stato il compimento della nuova Italia, ma che la nuova nazione deve nascere dalla rivoluzione [...] Egli ha vinto sugli uomini e sul tempo. Egli ha aperto agli uomini un nuovo secolo di ordine e di giustizia in un domani storico capace di indicare la via del risveglio. ${ }^{48}$

46 «Mario Puccini rievoca liricamente gli ultimi venti anni di Epopea italiana», Il Mattino d'Italia, 8 de septiembre de 1936.

47 «Una conferenza di Mario Puccini a Rosario», Il Mattino d'Italia, 20 de septiembre de 1936, 3. Camilla Cattarulla afirma: «Nella costruzione del consenso il fascismo innesta nel suo discorso ideologico quei miti e simboli del Risorgimento che riteneva utili a conquistare adesione e a rafforzare la propria identità politica» (Cattarulla, 2007, 305). El Risorgimento es interpretado, por tanto, como una revolución natural incompleta, en relación al cual el fascismo representa la culminación de la Independencia italiana. La autora señala también cómo a partir de la dirección de Intaglietta, en relevo de Appelius, Il Mattino «rende via a via più esplicito il suo ruolo di diffusione dell'ideologia fascista in Argentina se non organo del regime» y recuerda que el marco temporal que va de 1929 a 1936 incluye los denominados años del consenso (Ibidem, 304).

48 «La conferenza di Mario Puccini», Il Mattino d'Italia, 2 de octubre de 1936. 
Estas crónicas periodísticas, además de poner en primer plano la obra de italianidad llevada a cabo por los ilustres emisarios del régimen, informan de la expectación suscitada por el arribo de Puccini a las provincias del interior, alejadas de la agitación de la capital e interesadas en escuchar los distinguidos testimonios llegados desde la patria lontana. El perfil literario de los escritores queda relegado ante la prioridad política de su misión en ultramar, cuya pretensión principal parece ser la de robustecer los vínculos de lealtad entre las «colonias italianas» de la Argentina y la «madre patria»:

L'argomento prescelto dall'illustre scrittore non poteva essere migliore né essere accolto con maggiore entusiasmo fra gli italiani di Rosario che con lo sguardo fisso a Roma, con l'animo proteso verso il radioso futuro della patria, orientano i propri pensieri e i propri sentimenti verso il Capo che della nuova patria fascista. ${ }^{49}$

A su regreso a Buenos Aires, Puccini aprovecha los últimos días para ofrecer otras dos conferencias, la primera en Los Amigos del Arte, «Lo scrittore del nostro tempo», y la segunda en el Teatro Colón, dedicada a la figura del músico italiano Giovan Battista Pergolesi. Il Giornale d'Italia aprovecha la ocasión para reclamar un mayor espacio de representación en los escenarios argentinos para los artistas italianos:

Nell'organizzare questo spettacolo commemorativo del genio italiano, lo scrittore dimostrerà al pubblico ed ai suoi stessi dirigente quale sia la musica che meriti cittadinanza il quel teatro, quale sia l'arte vera, quella con A maiuscola verso la quale i signori del Colón hanno dimostrato in questi ultimi anni ben poche tenerezze..$^{50}$

El 5 de octubre, junto a Ungaretti en Santiago del Estero, Puccini vuelve a discurrir sobre «Le bellezze nascoste di Roma», y el día siguiente se despide de Buenos Aires con una conferencia titulada «Impressioni sulla Toscana», en la que propone un análisis del espíritu de la región a través de sus monumentos, tradiciones y obras de arte. Así como hiciera Bontempelli en su gira de 1933, también Puccini y Ungaretti recurren a las riquezas del pasado nacional para celebrar el presente refulgente de Italia. ${ }^{51}$

Por lo que se refiere a la agenda de actividades del poeta Giuseppe Ungaretti, sus páginas están igual de apretadas de compromisos que las de

49 «Una conferenza di Mario Puccini a Rosario», Il Mattino, 20 de septiembre de 1936, 3.

50 «Mario Puccini parlerà sul geniale artista», Il Giornale d'Italia, 4 de octubre de 1936.

51 Recuérdese a propósito de la tournée de Marinetti, la defensa de la superioridad de la raza italiana a través de figuras clásicas rescatadas de la tradición cultural nacional como las de Dante, Verdi o Puccini. 
su compatriota novelista, y también en este caso son los diarios italianos Il Giornale d'Italia e Il Mattino d'Italia los que siguen su travesía de manera más escrupulosa. Entre las primeras visitas de Ungaretti, destaca su paso por la redacción de La Nación, que publica una crónica del episodio y un retrato de ambos huéspedes al día siguiente:

Ayer visitaron La Nación el gran poeta y el eminente novelista italiano. Espíritus latinos por antonomasia, vivientes, claros y abiertos, Ungaretti y Puccini nos mostraron a través de agradables momentos de lucidez, la inteligencia de su mentalidad y la salud de su carácter. ${ }^{52}$

El desarrollo de la tournée ocupa también el punto de mira de los diarios opositores, en particular del cotidiano Crítica, que en un artículo firmado por el escritor italiano Mario Mariani invierte la imagen enaltecida de los intelectuales al señalar la corrupción que desprenden estos «escritores de baratillo, empleados de oficinas de propaganda, paniaguados de las dictaduras». Para Mariani, antifascista y exiliado, los tres huéspedes son meros agentes de propaganda que «no merecen ni fama ni identidad literaria», pues en un régimen de dictadura «el título de escritor lo otorga el gobierno». ${ }^{53}$ Estas descripciones encontradas de los visitantes, ubicadas en uno u otro ángulo del espectro político, saturan las páginas de la prensa de ultramar, pues el perfil fascista de la comitiva y las tensiones de la década en que se inscribe la visita impiden una acogida libre de carices ideológicos. Si para Crítica o L'Italia del Popolo resulta inadmisible la campaña de infiltración ideológica operada desde el marco cultural que se abre con las embajadas italianas, Il Mattino o Il Giornale se vanaglorian de la «seminazione di italianità fatta da Marinetti, da Ungaretti e da Puccini», célebres prototipos de la Nueva Italia. ${ }^{54}$

En su primera conferencia, «Il sentimento di Roma nella poesia del Petrarca», del 1 de septiembre, Ungaretti se dedica a demostrar la influencia de la poesía petrarquista en la literatura del siglo XVII y en autores como Leopardi y Goethe, y, luego, a poner de relieve la grandeza de Roma como centro de la cosmovisión artística del Petrarca, pero también como referente imperecedero de toda la literatura europea. Tal elección responde, una vez más, a la operación de exaltación nacionalista en que se opta

52 «Giuseppe Ungaretti y Mario Puccini», La Nación, 3 de septiembre de 1936.

53 «El escritor funcionario y la cruz roja del pensamiento», Crítica, 5 de septiembre de 1936.

54 «Mario Puccini e l'epopea italiana», Il Giornale d'Italia, 9 de septiembre de 1936. 
por una imbricación de las dimensiones de lo político y de lo cultural; de la misma manera que Puccini, en su charla sobre «Le bellezze nascoste di Roma», se desliza del plano estético al ideológico, Ungaretti hace uso de un referente literario para vertebrar el discurso centralista-romanista oficial.

El 4 de septiembre, y por iniciativa del Instituto Italiano de Cultura, Ungaretti lee en la Facultad de Filosofía y Letras su conferencia «Algunas observaciones sobre el desarrollo histórico de la poesía italiana», en la que diserta sobre la misión del poeta como intérprete de su época. Tras los encuentros del PEN Club, el 19 de septiembre comparece en la Dante Alighieri con la conferencia «Leopardi e il nostro tempo», que repite en Rosario el día 21; el poeta de Recanati se convierte en el epicentro desde el cual se traza una parábola que del terreno literario del pasado se proyecta hasta el presente político. El libro Canti prefigura la bisagra que entrelaza ambas cronologías pues era, según relata como testigo de los combates, «il bagaglio di molti nostri soldati nella grande guerra, eroi morti o sopravissuti». ${ }^{55}$ En la intervención, que Ungaretti aprovecha para rememorar su propio papel como soldado, ${ }^{56}$ las composiciones de carácter civil de Leopardi se ensartan con los axiomas del fascismo en un ejercicio de dudoso rigor interpretativo. De nuevo, el 3 de octubre en Córdoba, retoma el discurso sobre la pervivencia de Roma en la poesía petrarquista e insiste en las continuidades entre el mundo clásico y el tiempo presente. Al día siguiente, se reúne en Santiago del Estero con Mario Puccini, procedente a su vez de Bahía Blanca, y dicta la última conferencia de la tournée, dedicada a tres figuras monumentales de la tradición literaria italiana: Dante, Petrarca y Leopardi:

Giuseppe Ungaretti giunse a questa città procedente dalla dotta Cordoba. Egli fu ascoltato con intenso interesse. Più che una conferenza fu un analisi profonda ed originalissima di cinque secoli di poesia (....). Fu una rievocazione sublime di tempi e uomini colossalmente grandi. E mentre lui parla i suoi occhiettini celesti si aprono e si ingrandiscono in una visione di tempi magnifici, mentre il suoi viso si illumina della luce dei grandi. ${ }^{57}$

55 «Giuseppe Ungaretti agli Amici del'Arte», Il Mattino d'Italia, 20 de septiembre de 1936.

56 Ambos escritores asumen en su discurso oficial el protocolado por las instituciones del régimen. Si se atiende, en cambio, a la mirada íntima que descubre el intercambio epistolar entre ambos, los lamentos y las tentativas de fuga desdibujan la imagen del poeta-soldado siempre dispuesto para la batalla (Ungaretti, 2015).

57 «Due illustri ospiti», Il Mattino d'Italia, 5 de octubre de 1936. 


\section{Las miradas del viajero}

De la experiencia americana, Ungaretti no deja más testimonio que las conferencias recogidas, casi siempre de manera fragmentaria, en los periódicos de la época. Sin embargo, la crítica ungarettiana ha estudiado el impacto que las vivencias en ultramar, sobre todo las relativas a sus años en Brasil (1936-1942), han tenido en su poética y señala cómo, si bien el paso fugaz por Argentina deja pocas trazas en su creación lírica, la temporada en São Paulo marca con un signo indeleble la vida y la obra del poeta. ${ }^{58}$ De una entrevista concedida al diario argentino La Fronda se han rescatado algunas de las escasas declaraciones del poeta sobre la ciudad de Buenos Aires, en las que responde a una pregunta acerca de las sensaciones predominantes en su paso por la ciudad:

Suavidad, una gran suavidad. Yo creo que ustedes son un pueblo, en masa considerado, algo displicente, despreocupado, sin la avidez tormentosa de otras razas. Me dicen que la gente vive aquí con facilidad y comodidad. Maravilloso país en potencia que ha de darnos muy gratas sorpresas a los hombres de Europa. Quien como yo haya tenido exactas noticias de lo que era esta ciudad hace escasamente cincuenta años, tiene que sentirse asombrado en presencia de este inmenso monumento. Buenos Aires deja asombrado al viajero; asombra su extraordinaria vitalidad; su capacidad inmensa; su comercio potente. Se tiene la sensación de estar en un medio poderoso, pero de plena juventud. ${ }^{59}$

Ante la siguiente pregunta, referida a los altercados que han tenido lugar durante el congreso, Ungaretti reafirma la rectitud de la delegación italiana, cercada y desprotegida ante la «existencia de una parcialidad creada en forma desafortunada». Quizás sea el mismo periodista el que, dos días antes en el City Hotel, ha entrevistado también para La Fronda a Mario Puccini, quien al responder sortea el escándalo del PEN Club:

58 Diego Bentivegna (2010) identifica en el texto de Ungaretti Riflessioni sullo stile (1946) una de las pocas referencias a su paso por la Argentina que constituye un caso aislado; tras su regreso a Italia, las dos obras que publica son Il dolore (1947) y La terra promessa (1950), condicionadas por la muerte del hermano y del hijo durante su permanencia en Brasil y por los episodios trágicos de la Segunda Guerra Mundial. Ricardo H. Herrera y Raúl Antelo son los dos críticos argentinos que han centrado sus investigaciones en la estadía sudamericana del poeta italiano, cuyo barroco el primero considera que culmina «cuando Ungaretti logra poner en contacto dos realidades que son particularmente cercanas para nosotros: la lección lírica de Góngora y el carácter desmesurado, informe, de la realidad americana» (Herrera, 1998, 23). Por su parte, Antelo (2006) estudia el impacto que tiene en la poética de Ungaretti el encuentro con la hibridez americana.

59 «Ungaretti emite algunos conceptos para La Fronda», La Fronda, 16 de septiembre de 1936. 
¿Qué impresiones se lleva usted de Buenos Aires?

Entre ustedes los metropolitanos, y más extensamente entre los argentinos, hay mucho que observar, que elogiar, en suma, que comentar. [...] Buenos Aires da la sensación directa de lo que es, especialmente para el visitante extranjero: una ciudad acogedora a pesar de su inmensidad; de una población cálida en afectos. [...] La hospitalidad argentina es dulce y reconfortante. ${ }^{60}$

Puccini tampoco lamenta las incidencias provocadas y aprovecha la ocasión brindada por la entrevista para ensalzar a los escritores de la Italia fascista como aquellos que, nutriéndose «de aquella verdad maravillosa, asimilan en sus gustos y en sus tendencias, no solo la inquietud de la nueva era constructiva, sino las mismas aspiraciones de renovación». ${ }^{61}$ Otro artículo que merece atención es aquel en que Mario Puccini hace declaraciones a la prensa sobre su viaje a la Argentina y es publicado por Il Mattino d'Italia con el siguiente encabezamiento: «Il mio incontro con Buenos Aires. Parla (o meglio scrive) Mario Puccini». En él asoman dos ideas que van a vertebrar su libro L'Argentina e gli Argentini y que, por una parte, constatan el carácter de capital cultural de la ciudad anfitriona y, por otra, reivindican la mano de obra de la descendencia italiana en el proceso de construcción nacional:

Buenos Aires è in certo senso non solo la capitale dell'Argentina, ma spiritualmente ed intellettualmente parlando, anche dell' America Latina; cioè di un paese che risponde ad una volontà di vita profonda e da cui possono nascere fatti e cose di notevole significato per il mondo [...] Ho trovato degli italiani e ne trovo ogni giorno. Sento con piacere che la nostra lingua è molto intesa e parlata in Argentina. Brava gente è la nostra e che lavora con fede e con gioia. Mi interessano poi anche gli argentini nati dagli italiani; sono argentini e lo dicono ma credono anche al loro paese d'origine e lo amano; non si può dimenticare una tradizione di gloria, non si può perdere senza dolor e senza dramma un contatto che onora. Quello che conta, ripeto, è questo: che essi mantengano vivo per sé per i futuri il contatto spirituale con le radici da cui un

60 «Mario Puccini habla para La Fronda», La Fronda, 14 de septiembre de 1936.

61 Idem. Marinetti, en su autobiografía publicada de manera póstuma, dedica algunas páginas a recordar sus peripecias porteñas, entre ellas la reunión del PEN Club: «Non so quanti anni fa a Buenos Aires sfidavo sarcasticamente i congressisti francesi del PEN Club che mi accusavano di italianità prepotente ma è certo che rimasero male quando si alzò lo scrittore giapponese Hiraschiovara per improvvisare un lungo elogio dell' Italia in lingua italiana»; y a propósito de Victoria Ocampo recuerda: «la faccio piangere denigrando con molte carezze le sue teorie comuniste, la sua incomprensione dell'adorato Mallarmé per modo che ributtando gli attacchi di Romains Crémieux e quelli che mi piovono dal loggione dei comunisti italiani sono applaudito e richiamato alla ribalta non come Gigli ma come un torero spagnolo capace di colpire e rintuzzare tutte le banderuole da toro italiano» (Marinetti, $1969,323)$. 
giorno furono nutriti; lo spirito ha ragioni di forza e di presa, lo spirito vive e resiste contro tutti i richiami materiali ed immediati. ${ }^{62}$

Quizás con la intención de nutrir este vínculo entre los italianos de Argentina y su país de origen, Puccini escribe a su regreso a Italia su libro L'Argentina e gli argentini, publicado en Milán por Garzanti Editore en 1939. El texto, enmarcado por la advertencia «L'Argentina è un paese ancora in pieno travaglio creativo e costruttivo», está dividido en tres capítulos en los que se incluyen un total de ciento ochenta y ocho fotografías y tres mapas. Puccini adopta un tono lírico y entusiasta para llevar a cabo una búsqueda íntima que tiene como propósito desvelar la «vita aperta e segreta di quel paese e di quel popolo». ${ }^{63} \mathrm{El}$ resultado de la reelaboración de sus notas de viaje es una suerte de guía para el viajero o manual para el curioso.

En el primer capítulo, «ll Paese», de carácter histórico y geográfico, se introduce al lector en materia con una serie de datos objetivos sobre el nacimiento y la consolidación del Estado argentino. En él se describen con precisión sus ciudades principales (Buenos Aires, Tucumán, Santiago del Estero, Santa Fe, Córdoba, Rosario, La Plata, Mendoza, Bahía Blanca y Corrientes), se traza un mapa de su majestuosa red hidrográfica y se delinean sus principales áreas geográficas (La Pampa, El Chaco, Los Andes y el Sur o Tierra del Fuego). Buenos Aires es descrita como un ciudad en perpetuo cambio, «non si crederà mai ad un'Argentina addomesticata, assestata, docile, contenta: domani queste piazze che ammiriamo, queste arterie che ci impressionano per la loro potenza e veemenza potrebbero ancora mutare». ${ }^{64}$ Estas tierras —advierte Puccini al lector europeo- han de ser contempladas con «innocenza e castità», pues su peculiaridad reside en la mezcla y la discordancia. El apetito de armonía y la búsqueda de la originalidad deben contenerse en el acercamiento a lo americano, pues cada uno de sus monumentos, si trasladados a Europa, desafinarían por su desproporción y «stonatura». La descripción de la pampa va ligada en la escritura de Puccini a un elogio de la potencia creadora del pueblo argentino por su capacidad de someter esa geografía inhóspita, inmensa y deshabitada al dominio del hombre, arraigando nuevos mitos en una tierra con un pasado despojado de mitologías:

62 «ll mio incontro con Buenos Aires. Parla (o meglio scrive) Mario Puccini», Il Mattino d'Italia, 1 de septiembre de 1936, 1.

63 Puccini, 1939, I.

64 Ibidem, 23. 
C'è una pampa che si potrebbe chiamare letteraria, ideale ed una Pampa autentica, reale, viva e vivente. Della prima, si parla molto: e non solo dai lontani, anche e soprattutto dagli Argentini. Bisogna subito farci i conti e sbrigarsi con questa Pampa: come tutte le cose che la fantasia umana troppo a lungo e compiacentemente ha accarezzate, essa è diventata quasi un cliché. [...] È nella Pampa e per la Pampa che l'Argentina trova veramente se stessa, cioè le sue virtù di costanza e di forza, quelle virtù che determineranno la sua potente fisionomia. [...] L'Argentina civile è quella che ha addomesticato la Pampa con la vanga e con l'aratro, quella che ha robustamente creduto nella sostanza viva di quella terra. ${ }^{65}$

En tal obra de civilización de la tierra bárbara, además de los poetas, Puccini reivindica el papel indiscutible de los contingentes de inmigrantes. En ella, desde los tiempos de la colonia, el «gringo» ha desarrollado un rol fundador, primero a través de los comerciantes genoveses y después, a partir de la era aluvional, de sus campesinos, muchos de ellos pobladores de «la pampa gringa». ${ }^{66}$

\begin{abstract}
Abbastanza omogeneo, materialmente e moralmente, l'apporto della nostra emigrazione, dell'emigrazione dei contadini e dei lavoratori italiai. In verità, l'Italia non era assente neanche ai tempi della Conquista: vari marinai delle navi di Juan Solis erano italiani: a Buenos Aires nata, si muovono sulle rive del Riachuelo commerciati della nostra Liguria. Ma l'emigrazioni dell'ultimo Ottocento portano laggiù delle masse imponenti di uomini nostri; e sono queste masse a inaugurare un'epoca agricola seriamente attiva e produttiva: la Pampa fu chiamata gringa dal nomignolo che si dava agli italiani, i quali l'avevano dirozzata e ingentilita: un nomignolo che voleva indicare lo straniero, e non senza disprezzo; ma che oggi vale quanto una patente di nobiltà: se il gringo fosse mancato, la Pampa non sarebbe diventata quel giardino che oggi è: fu il lavoro del gringo, fu la costanza del gringo, fu la fede del gringo a creare, o almeno, ad aiutare la ricchezza del paese. ${ }^{67}$
\end{abstract}

El segundo capítulo, «Costumi, ideali, caratteri della città della strada e della casa», se abre con una indagación en la psicología del hombre argentino, definido por su carácter combativo: esa inmensidad vacía y salvaje, el siempre lejano horizonte, explica en buena medida la paciencia y la laboriosidad de su pueblo. No podía faltar en el texto de Puccini la referencia al hombre de la pampa y a la historia de su declive. Gaucho e inmigrante aparecen enfrentados en una lucha no de cuerpo a cuerpo sino de laboriosidad: si bien el gaucho es el más fuerte a caballo por su ágil dominio del

65 Ibidem, 82.

66 Véase Gallo (2006), para un estudio en detalle de esta vasta región, fundamental a la hora de entender los orígenes de la Argentina moderna.

67 Puccini, 1939, 119. 
animal, la dependencia de la carne y del mate lo hacen más débil frente a su contrincante. Por el contrario, el italiano es capaz de trabajar tenazmente alimentándose poco o nada. El inmigrante, en la visión de Puccini, vence al gaucho: mientras uno ha desaparecido, el otro se ha adueñado de la pampa y su conquista se lee como signo crucial de la capacidad de la raza.

Oggi come oggi, sono spariti, nonché i gauchos, ma anche i loro figli: e sapete chi li ha fatto allontanare, o almeno, chi ne ha aiutata la lenta, ma inesorabile decadenza? Fu il contadino. E soprattutto il contadino venuto dall'Italia; quando non erano ancora cominciate le grandi emigrazioni in massa, la Pampa coltivata era una porzione esigua: la coltivazione intensiva e regolare del territorio fu opera quasi esclusiva dell'emigrato italiano. ${ }^{68}$

El interés del testimonio de Puccini acerca de la región visitada radica para nosotros en la conexión que establece entre el progreso de la República Argentina y la labor del inmigrante italiano, al que se adjudica un papel clave en el desarrollo de la joven república sudamericana, contraviniendo los prejuicios anti-inmigracionistas que vuelven a circular entre los nativos en los años treinta. Puccini elabora su particular ensayo de interpretación nacional, en el que recupera el mito de la laboriosidad del inmigrante, aquel que tras haber contribuido a la fertilidad del suelo pampeano y a la edificación de las ciudades modernas en el país de acogida, es señalado por las oligarquías criollas a lo largo del primer tercio del siglo XX como sujeto advenedizo y corruptor de la argentinidad.

\section{Balance}

La visita a Buenos Aires del trío fascista compuesto por Marinetti, Ungaretti y Puccini, con ocasión del Congreso Internacional del PEN Club, ha de ser leída como un episodio de carácter eminentemente político. A pocos meses del comienzo de la guerra civil española y ante los nuevos espacios conquistados por las fuerzas del totalitarismo en Alemania y en Italia, el desembarco de los tres escritores italianos convulsiona con fuertes polémicas al campo intelectual bonaerense y convierte el encuentro de «Poetas, Ensayistas y Novelistas» en un campo de batalla. Las turbulencias que sacuden los paisajes políticos argentino y europeo acaparan los espacios de

68 Ibidem, 144. 
discusión de los escritores, que, obligados a asumir su compromiso ante la gravedad de los acontecimientos, se dividen entre partidarios de la democracia y defensores del fascismo. El papel desempeñado por la delegación italiana en este contexto de crispaciones poco tiene que ver con querellas de índole artístico: su encuentro con la comunidad intelectual argentina entre el 5 y el 15 de septiembre de 1936 se resume en una sucesión de agravios entre congresistas y su participación en las reuniones queda marcada por las incidencias y los encontronazos de tipo ideológico.

Las actividades de los viajeros fuera del congreso demuestran el carácter propagandístico que el régimen fascista impone a las intervenciones culturales de sus emisarios: «en cada conferencia, el hecho literario sirve para ilustrar el dato histórico, las artes brindan la materia para el panegírico y las figuras de autoridad de la tradición italiana son instrumentalizadas con una finalidad abiertamente política». ${ }^{69}$ Los artefactos culturales son los vasos comunicantes de la campaña de italianidad llevada a cabo por los ilustres visitantes, en cuyas conferencias confluyen siempre los mismos tópicos: la grandeza de Roma, la epopeya italiana, las victorias africanas y la juventud de la Italia Nuova. La utopía fascista, traída de la mano de sus ilustres intelectuales, tiene también una aspiración de orden artístico: a su prestigio como nación moderna, los argentinos han de corresponderle con una posición central de sus artistas en el campo cultural transatlántico.

Este desembarco es el detonante de una fuerte contienda en la prensa argentina, con un énfasis particular en los diarios italianos. A lo largo del mes y medio que dura su estadía, los visitantes protagonizan las crónicas periodísticas, que pasan por alto su condición de literatos y recrean las figuras de los intelectuales bien como poetas soldados del Imperio italiano bien como agentes de propaganda. La recepción de la comitiva en el medio local no puede desvincularse de su halo político: el lugar que ocupan en el tablero político es el que condiciona la hostilidad de un Mario Mariani o el entusiasmo de un Gálvez o de un Ibarguren. La visita es, en esta ocasión, una pieza clave del aparato fascista que se encuentra en un año de pleno apogeo: la reciente guerra en Etiopía influye en las semblanzas de los escritores, más que nunca poetas combatientes de una Italia imperial, la expresión más sofisticada de su nueva era. La comitiva de los tres escritores no puede leerse al margen de los planes de fascistización previstos por las instituciones del régimen para los territorios de ultramar, poblados de manera masiva

69 De Aldama, 2018, 80. 
por inmigrantes italianos desde finales del siglo XIX. El desembarco del 36 brinda entonces una ocasión idónea para exaltar las glorias del Duce y organizar el consenso de los expatriados en torno a su ideario. Así como los intelectuales italianos cumplen un papel clave en la consolidación del régimen dentro de las fronteras de la nación, sus embajadas transatlánticas suponen una herramienta privilegiada para operar en el extranjero desde lo cultural, evitando una intervención explícitamente política.

El paso de los tres emisarios por la capital permite la activación de recursos propios de la liturgia fascista: las conferencias, entrevistas y homenajes que tienen lugar en Argentina se convierten en el escenario donde venerar los símbolos, las creencias y los mitos de la Italia Nuova, revisitando así el pasado y el presente nacional de acuerdo con los presupuestos de la cosmovisión totalitaria del Duce. A través de un concienzudo ejercicio de exhibicionismo y espectacularización, centrado en la exaltación de sus «hombres nuevos», osados, jóvenes y viriles, la prensa fascista busca la adhesión de los «italianos de Argentina» al régimen que predica. De la misma manera que Mussolini envía en 1924 hacia los puertos latinoamericanos la Crociera Nave Italia, cargada de los más exquisitos ejemplares del arte y la industria nacionales, el desfile de los intelectuales por las páginas de las crónicas busca revertir la imagen desvencijada de la nación italiana anterior a 1922. El cuerpo del intelectual se convierte así en emblema de la italianidad y deviene, por relación metonímica, cuerpo de la nación: el viajero no es un mero agente de propaganda sino que encarna el imaginario triunfal del régimen, es el «hombre nuevo» en unión sagrada con el destino de la patria. Arte y propaganda quedan, por tanto, perfectamente ensamblados, aunque son los intereses del régimen los que van a imperan sobre los postulados estéticos. Así lo constatan las embajadas transatlánticas de estos escritores, que quedan a merced de la tormenta de ideas que domina el campo intelectual de la década del treinta, deviniendo objeto del mensaje ideológico que ellos mismos se encargan de transportar desde las costas italianas a las orillas rioplatenses.

Los desembarcos de los escritores vienen a exacerbar las tensiones que atraviesan la sociedad argentina, convirtiéndose en el detonante de nuevas disputas. A su llegada, los emisarios del régimen abren un nuevo frente de batalla, un marco privilegiado desde donde intervenir en la contienda que fractura, de manera cada vez más abrupta, la comunidad intelectual local entre fascistas y antifascistas. Tales enfrentamientos se dan con especial virulencia en el interior de la comunidad italiana de ultramar, cuyos 
integrantes se dividen en los mismos bandos que se enfrentan en Italia, reproduciendo en la lejanía transatlántica las guerras que afligen a la patria de origen. Sin embargo, no solo la comunidad italiana sufre tal escisión, sino que esta irrumpe también en el campo intelectual argentino, que vive de cerca los enfrentamientos europeos. Si ante los emisarios fascistas que desembarcan en los años treinta Buenos Aires se despliega en un panorama de fuertes pugnas, el carácter político de sus travesías viene a exasperar el conflicto instaurado entre las facciones enfrentadas. La nación argentina en su conjunto, ligada a Italia por múltiples lazos culturales y, sobre todo, por los flujos de población procedentes de sus territorios en las últimas décadas, deviene entonces una caja de resonancia en la que retumba el fragor de la contienda europea.

\section{Referencias bibliográficas}

Antelo, Raúl, María con Marcel. Duchamp en los trópicos, Buenos Aires, Siglo Veintiuno, 2006.

Bentivegna, Diego, «Memoria y pobreza: Ungaretti en Santiago del Estero», $\mathrm{Ha}$ blar de poesía, 22, Córdoba, 2010, 139-157.

Binns, Niall, Argentina y la guerra civil española. La voz de los intelectuales, Madrid, Calambur Editorial, 2012.

Cattarulla, Camilla, «Orgoglio italiano: la propaganda fascista in Argentina attraverso il Risorgimento», Studi latinoamericani / Estudios latinoamericanos, 3, Udine, 2007, 301-316.

De Aldama Ordóñez, Celia, «La parola contesa: inmigrantes y viajeros italianos en el campo intelectual argentino (1900-1936)», tesis doctoral, Madrid, Universidad Complutense, 2017, https://eprints.ucm.es/45374/1/T39360.pdf.

De Aldama Ordóñez, Celia, «Marinetti, Puccini y Ungaretti: tres embajadores de las letras italianas en la Argentina», en Patat, Alejandro (ed.), La letteratura italiana nel mondo iberico e latinoamericano. Critica, traduzione, istituzioni, Pisa, Pacini Editore, 2018, 71-81.

Gallo, Ezequiel, La pampa gringa: la colonización agrícola en Santa Fe (18701895), Buenos Aires, Corregidor, 2006.

Giusti, Roberto F., «El Congreso de los P.E.N. Clubs. Comentario a puertas cerradas», Nosotros, Segunda Época, 6, 1936, 48-64.

Guglielmino, Salvatore, Il sistema letterario. Novecento, Milano, Principato, 1994. 
Manzoni, Celina, «Buenos Aires 1936. Debate en la República de las Letras», Hispamérica, 100, EE.UU., 2005, 3-18.

Marinetti, Filippo Tommaso, La Grande Milano Tradizionale e Futurista. Una sensibilità italiana nata in Egitto, Verona, Arnoldo Mondadori Editore, 1969.

Melfi, Domingo, El Congreso de Escritores de Buenos Aires (notas e imágenes), Santiago de Chile, Nascimento, 1936.

Palacio, Ernesto, «Ungaretti», Sur, VI, 23, Buenos Aires, agosto de 1936, 56.

Puccini, Mario, L’Argentina e gli argentini, Milano, Garzanti Editore, 1939.

Shirkin, Susana, «La letra asediada. El avance del nacionalsocialismo sobre el campo literario y teatral y sus repercusiones en la Argentina de los años treinta», Serie Documentos de Trabajo, 03, IDICSO, Universidad del Salvador, 2007.

Trento, Angelo, «I viaggiatori italiani in America Latina in era fascista tra curiosità e ideologia», en Moricola, Giuseppe (ed.), Il viaggio degli emigranti italiani in America Latina tra Ottocento e Novecento. Gli aspetti economici, sociali, culturali, Napoli, Alfredo Guida Editore, 2008, 135-180.

Ungaretti, Giuseppe, Sentimento del tempo, Barcelona, Galaxia Gutenberg / Círculo de Lectores, 1998.

Ungaretti, Giuseppe, Lettere dal fronte a Mario Puccini, Milano, Archinto, 2015. 